\title{
Obstetric and neonatal outcomes of adolescent pregnancy
}

\author{
Tuncay Yuce, Seda Sahin Aker, Mehmet Murat Seval, Erkan Kalafat, Feride Soylemez \\ Department of Obstetric and Gynecology, Ankara University Faculty of Medicine, Ankara, Turkey
}

\begin{abstract}
OBJECTIVE: We performed a retrospective study to evaluate adolescent pregnancies as for gestational complications, and prinatal outcomes.

METHODS: We evaluated 341 pregnants whose data we could reach regarding gestational, and perinatal complications.

RESULTS: In our study group anemia (35.4\%), preeclampsia/eclampsia (1.45\%), premature membrane rupture $(1.4 \%)$, intrauterine growth retardation $(3.81 \%)$, and instrumental delivery $(0.3 \%)$ were seen in indicated incidence rates.

CONCLUSION: In our retrospective study, we found lower our complication rates in adolescent age group when compared with the adult age group, and other studies performed in adolescents. Since our hospital is a tertiary health care institute, and we monitorized our patients closely, our incidence rates can be better than those cited in the literature. As long as proper antenatal surveillance is employed, adolescent mothers do not seem to have increased risk for most of obstetric complications.
\end{abstract}

Keywords: Adolescent pregnancy; cesarean ratio; fetal outcomes; maternal complication.

A dolescent pregnants have been defined as pregnant women aged between $13-19$ years It is a prominent health problem in all the world. Based on the data of The World Health Organization, every year approximately 16 million deliveries are realized in this age group [1].

Globally, adolescent birth rates for each 1000 births between the years 2010, and 2014 were 0.051 in South Africa, 0.031 in The United States of America (USA), 0.026 in the UK, 0.008 in Ire- land, and 0.009 in China. Among all countries of the world, the highest rate $(205 / 1000)$ belongs to Nigeria. For each 1000 women between the ages of 15-19 years, the highest adolescent birth rate is detected in the Central Africa (137/1000), and the lowest rate (4.8) is found in the Western Europe Three countries with the lowest birth rates among adolescents in the 15-19 age bracket are Slovenia (0.0006), Northern Korea (0.0006), and Switzerland $(0.0019)$ [2]. In our country $16.7 \%$ of

Received: January 05, 2015 Accepted: July 09, 2015 Online: September 24, 2015

Correspondence: Dr. Tuncay YUCE. Ankara Universitesi Tip Fakultesi, Cebeci Hastanesi Kadin Hastaliklari ve Dogum Anabilim Dali, 06620 Mamak, Ankara, Turkey. 
our population consist of people in the adolescence age group. In our country adolescent birth rate was 0.024 in the year 2013. Fertility rate is at its highest in the province of Agri. In the year 2012, 9.5\% of the adolescent mothers were not married, while $90 \%$ of them were officially married [3].

The differences in complication rates between adolescent, and adult pregnancies have not been explained clearly. Although some studies have yielded clear-cut opinions, explicit outcomes have not been reported especially regarding preeclampsia, abortus, nutritional disorders, gestational diabetes, and other gestational complications [4].

While we were planning this study, we aimed to investigate if maternal complications seen in pregnants aged 13-19 years who gave birth in our clinic are different when compared with those of the normal adult population, and adolescent groups analyzed in other studies.

\section{MATERIALS AND METHODS}

Adolescent pregnants aged less than 19 years who presented to the Clinic of Obstetrics, and Gynecology of Ankara University Faculty of Medicine between January 2008, and September 2014 were included in the study. We evaluated these pregnants as for the presence of preeclampsia, eclampsia, intrauterine growth retardation (IUGR), premature membrane rupture (PMR), gestational cholestasis, premature labour, fetal malformation, mode of birth, and hospitalization rate of newborns in in- tensive care unit In this age group 353 adolescents gave birth, and data of 12 patients were not available, so they were excluded from the study.

Statistical analysis, and distribution range of data, and their incidence rates were calculated using SPSS 21.0 program. Parametres with normal, and non-normal distribution were evaluated using t-test, and Mann-Whitney $\mathrm{U}$ test, respectively. $\mathrm{Pa}$ rameters with $p$ value of $<0.05$ were considered to be statistically significant.

\section{RESULTS}

Data of 341 adolescent pregnants were included in the study. Characteristic features of the patients have been given in detail in Table 1.

Adolescent pregnants were also evaluated as for mode of delivery, and pregnants gave birth via vaginal delivery $(\mathrm{n}=242 ; 70.96 \%)$, and cesarean section $(\mathrm{n}=99 ; 29.04 \%)$ Singleton, and twin adolescent pregnancies were detected in 339, and $2(0.52 \%)$ patients, respectively. Seven (2\%) patients gave normal birth by induction. Modes of delivery, and indications of cesarean section are given in Tables 2 , and 3 , respectively.

During monitorization of the pregnants, an abnormal finding was detected in $54.99 \%$ of the pregnants. Anemia was the most frequently encountered symptom. All detected complications are summarized in Table 4.

Preterm delivery (before 37. gestational week)

TABLE 1. Characteristic features of adolescent pregnants

\begin{tabular}{lccc} 
& Mean \pm SD & Minimum & Maximum \\
\hline Gravida & $1.08 \pm 0.30$ & 1 & 3 \\
Parity & $0.04 \pm 0.2$ & 0 & 1 \\
Age & $17.58 \pm 0.65$ & 15 & 18 \\
Gestational week & $38.6 \pm 1.83$ & $41^{*} 5$ & $26^{*} 2$ \\
Birthweight & $3130.7 \pm 491.5$ & 830 & 4700 \\
Apgar score 1. min & $8.25 \pm 0.94$ & 3 & 10 \\
Apgar score 5. min & $9.52 \pm 0.59$ & 6 & 10 \\
Hemoglobin & $11.5 \pm 1.48$ & 7.6 & 17.4
\end{tabular}


was seen in 31 (9\%) of the adolescent pregnants, while $12 \%$ of the newborns were hospitalized in the intensive care unit.

Regarding fetal malformations, sacrococygeal teratoma $(n=2)$, fetal meningomyelocele $(n=2)$, fetal cardiac arrhytmia $(\mathrm{n}=1)$, and micropenis associated with cryptoorchidism $(n=1)$ were detected. Any perinatal mortality was not seen.

\section{DISCUSSION}

Adolescent pregnancies continue to be a health problem worldwide [2]. Adolescent births have been associated with lower socioeconomic, and educational level, ethnic, and cultural factors, and religious beliefs. However fertility rates increase with age. In our country, fertility rates are 1 , and $13 \%$ in adolescents aged $<15$, and at 19 years of age, respectively [3].

After registration of pregnancies especially in this age group, the incidence of these complications, and whether adolescent pregnancy is a risk factor or an ineffective issue for these complications have become a current issue. In their study in the year 1995, Mahfouz AA et al. stated that adolescent pregnancy is a risk factor by all means which leads to low birthweight, instrumental delivery, anemia, intrauterine growth retardation, abortus, nutritional disorder, and inadequate antenatal surveillance. They also indicated that a satisfactory antenatal care would eliminate this risk [5]. Still in a study conducted by Imir GA et al, as confirmed by many other studies, higher rates of preterm delivery, eclampsia, and abortus have been reported [6]. Liu $\mathrm{X}$ et al. reported higher rates of anemia (1.4-fold), preeclampsia (1.6-fold), preterm delivery (2.1-fold), low birthweight (2.3-fold), and perinatal mortality (3.6-fold) among pregnant women aged 25-29 years of age [7].

Despite all of these studies, when compared with normal adult pregnancies, differences in the incidence of abortus, low birthweight, infection, toxemia, preeclampsia, anemia, intrauterine growth retardation risks in adolescent pregnancies have not been clearly stated $[8,9]$. Contrary to other studies in our study we observed lower preeclampsia/eclamp-
TABLE 2. Mode of delivery

\begin{tabular}{lcc} 
& $\mathrm{n}$ & $\%$ \\
\hline Vaginal delivery & 242 & 70.96 \\
$\quad$ Delivery using right & & \\
mediolateral episiotomy & 239 & 70.08 \\
Normal vajinal delivery & 2 & 0.58 \\
Forceps & 1 & 0.30 \\
Cesarean delivery & 99 & 29.04
\end{tabular}

TABLE 3. Indications of cesarean section

\begin{tabular}{lcc} 
& $\mathrm{n}$ & $\%$ \\
\hline Fetal distress & 36 & 36.36 \\
Malpresentation & 20 & 20.21 \\
Non-progressive labour & 18 & 18.18 \\
cephalopelvic disproportion & 10 & 10.1 \\
Previous cesarean & 6 & 6.06 \\
Eclampsia/preeclampsia & 3 & 3.03 \\
Maternal disease & 2 & 2.02 \\
Fetal meningomyelocele & 2 & 2.02 \\
Fetal sacrococcygeal teratoma & 1 & 1.01 \\
Maternal request & 1 & 1.01 \\
Total & 99 & 100
\end{tabular}

TABLE 4. Obstetric complications

\begin{tabular}{lcc} 
& $\mathrm{n}$ & $\%$ \\
\hline Preeclampsia & 3 & 0.87 \\
Eclampsia & 2 & 0.58 \\
Itrauterin growth retardation & 13 & 3.81 \\
Premature membrane rupture & 5 & 1.46 \\
Premature labour & 3 & 0.87 \\
Gestational cholestasis & 3 & 0.87 \\
Polyhydoamniosis & 2 & 0.58 \\
Oligohydoamniosis & 5 & 1.46 \\
Anemia & 121 & 35.4 \\
Preterm delivery & 31 & 9.09 \\
Total & 157 & 54.99
\end{tabular}


sia rates when compared with the adult pregnancies.

However in a study performed by Astha $\mathrm{R}$ et al. the authors indicated that rates of cesarean sections performed were 1.6-fold higher in the adolescent pregnancy group when compared with the adult pregnancies because of preeclampsia, eclampsia, PPROM, antepartum, and postpartum bleeding, and nonprogressive labour (44, and $21 \%$, respectively) [10]. Especially in studies investigating maternal age, and birthweights, preterm birth rates among pregnants aged less than 16 years were 1.8 times higher relative to those aged $20-29$ years [11]. Besides, maternal comorbidities (HIV; malaria, syphilis, tuberculosis, hypertension, and maternal infection) are seen more frequently in adolescents [10]. In our study preterm delivery was seen in $9.09 \%$ of the adolescents. Lower rates of these complications might be related to scarce number of patients aged less than 16 years of age. As another assumption for our lower rates of complications, since our hospital is a university hospital, our patients are regularly followed up.

Perinatal mortality rates were analyzed, and stillbirths (5.5/1000), perinatal (8.9/1000), and neonatal $(4.4 / 1000)$ mortality rates were detected in respective percentages which were seen to be higher when compared with the adult population. In the adolescent groups, prematurity, and neonatal mortality rates were 2 -fold higher relative to adult groups [12]. A certain proportion (9.6\%) of neonatal mortality consisted of pregnants younger than 20 years of age [12]. The most frequently seen etiologies were prematurity, and low birthweight (29\%), neonatal infections (25\%), birth trauma, and asphyxia (23\%), congenital anomalies (8\%), neonatal tetanus (2\%), and diarrhea (2\%) [13].

In Africa, maternal age of $50 \%$ of the mothers is less than 20 years of age. Neonatal mortality rates in mothers aged $<15,16-17$, and 18-19 years are 55, 19 , and $6 \%$, respectively These neonatal mortality rates are higher than those seen in pregnants older than 20 years of age [14].

In a study performed by Astha $\mathrm{R}$ et al. pregnancy rates between African adolescents, and adults were compared, and incidence rates were detected as $3968 / 1000$, and $2347 / 1000$ among adolescents, and adults, respectively. Educational level in adolescents, and their families was markedly lower, while among adolescents unmarried women were more numerous. In the adolescent group separate parents were more frequently seen. In adolescents first-time pregnancy rates were 2.2-fold higher [10].

In our study, first-time pregnancies were seen in 95.61\% of the adolescent women. Contrary to other studies, probably the most diverse outcome of our study is that we haven't encounter any case of perinatal mortality. Fetuses with anomalies were successfully operated during the neonatal period.

We investigated mode of delivery of our patients, and found rate of cesarean section (C-S) as 29.04 percent. In literature studies $\mathrm{C}-\mathrm{S}$ rates ranging between 20 , and $30 \%$ have been reported [ 6 , $15,16]$. Indicates of cesarean section include acute fetal distress (31.3\%), malpresentation (23.3\%), and previous C-S (22.2\%) [6]. However in our study, indications of C-S were acute fetal distress (36.3\%), malpresentation (20.2\%), nonprogressive labour (18.1\%), and cephalopelvic disproportion (10.1\%).

In the Turkish population of all age groups, incidence rates of low birthweight (9.5\%), preterm delivery $(13 \%)$, congenital anomaly (1.5\%), stillbirth $(1.8 \%)$, and early neomnatal death $(1.7 \%)$ are as indicated in parentheses [17]. In our study rates of IUGR, premature labour, and congenital anomalies were 3.81, 9.09 and $1.46 \%$, respectively.

In a study by Yildirim et al. obstetric complications in adolescent pregnancies consisted of low birthweight $(28.7 \%)$, gestational hypertension $(23.4 \%)$, anemia $(21.8 \%)$, and forceps/vacuum assisted delivery (21.6\%). In the same study 5. min mean APGAR score was $8.9 \pm 0.9$ points [18]. In our study mean APGAR scores were 8.25 \pm 0.941 , and $9.52 \pm 0.59$ at 1 , and 5 . minutes, respectively. We haven't encountered any incident of vacuum assisted delivery. We observed one case of forceps delivery.

Imir et al. reported that the incidence of development of eclampsia in adolescent pregnants was significantly higher when compared with the adult pregnants ( 5 vs $1.5 \%$ ). However, any significant dif- 
ference was not observed in the incidence rates of HELLP syndrome, and preeclampsia [6]. In our study, preeclampsia $(n=3 ; 0.87 \%)$, and ecalmpsia $(\mathrm{n}=2 ; 0.58 \%)$ were also encountered.

In a study performed by Melekoglu et al. preterm labour $(37.5 \%)$, preeclampsia $(31.3 \%)$, intrauterine growth retardation (20\%), fetal distress $(20 \%)$, congenital anomalies $(16.3 \%)$, and anemia $(40 \%)$ were seen in adolescent pregnants in respective incidence rates. As reported by the authors, they were statistically significantly higher relative to the adult group [19].

In a study by Keskinoglu et al. the incidence of oligohydramnios was found to be 0.2 percent [20]. In our study, in $1.46 \%$ of adolescent pregnants oligohydramnios was detected. Besides, they estimated incidence rate of congenital anomalies as 1.1 percent [20]. However according to Demir et al. its incidence was 3.6 percent [21]. In our study we observed congenital anomalies in $1.46 \%$ of our adolescent pregnants.

In various studies, incidence of gestational cholestasis has ranged between 0.1 , and 15.6 percent. Gestational cholestasis progresses with prematurity, and fetal complications as meconium aspiration syndrome, and intrauterine death [22]. In our study gestational cholestasis was seen in $0.87 \%$ of our patients which is in compliance with the literature.

In our country $40.2 \%$ of the pregnants have been indicated to have iron deficiency anemia [23]. In a study by Tekbas et al. its rate was reported as 17.2 percent. They indicated incidence rates of this type of anemia in the first, second, and the third trimesters as $10.4,21.5$, and $27.7 \%$, respectively [24].

In a study by Bozyel et al. overall incidence of anemia was reported as 25.4 percent. Incidence rates of anemia in pregnants were indicated as $33.3 \%$ in the $15-19$, and $22.7 \%$ in the $20-35$ age groups [25]. In another study overall prevalence of anemia was found to be $42.4 \%$, while prevalence rates of anemia were $59.4 \%$ in pregnants aged $\leq 19$ years, $40.8 \%$ in $20-29,39.5 \%$ in $30-39$ age groups, and $25 \%$ in pregnants aged $\geq 40$ years [26]. In our study, anemia was observed in 121 (35.4\%) pregnants in their 3, trimesters.
Even outcomes of our study seems to be favourable, the greatest limitation of our study is that our hospital does not completely reflect average sociocultural level of our country, because of its location.

In conclusion, in our country, adolescent pregnancy rate is very high, and majority of the total population is delivered by adolescent pregnants. This condition is a very important health problem both in all the world, and in our country. This phenomenon should be corrected by training, and legal approaches. However despite all of these measures, we should provide detailed information about appropriate prenatal care, antenatal surveillance, adequate nutrition, and then contraception to our pregnant patients.

Conflict of Interest: No conflict of interest was declared by the authors.

Financial Disclosure: The authors declared that this study has received no financial support.

\section{REFERENCES}

1. WHO. Early marriages, adolescent and young pregnancies. Report by the Secretariat. A 65/13. Geneva, Switzerland: WHO; 2012.

2. Adolescent fertility rate (births per 1000 women ages 15-19); http://data.worldbank.org/indicator/SP.ADO. TFRT?order=wbapi_data_value_2012+wbapi_data_ value+wbapi_data_value-last\&sort $=$ asc.

3. Türkiye İstatistik Kurumu, İstatistiklerle Çocuk, 2013; http:// www.tuik.gov.tr/PreHaberBultenleri.do?id=16054.

4. Fraser AM, Brockert JE, Ward RH. Association of young maternal age with adverse reproductive outcomes. N Engl J Med 1995;332:1113-7.

5. Mahfouz AA, el-Said MM, al-Erian RA, Hamid AM. Teenage pregnancy: are teenagers a high risk group? Eur J Obstet Gynecol Reprod Biol 1995;59:17-20.

6. İmir G, Çetin M, Balta O, Buyukkayhan D, Cetin A. Perinatal outcomes of adolescent pregnancies at a university hospital in Turkey. J Turkish-German Gynecol Assoc 2008;9:70-5.

7. Liu X, Zou L, Chen Y, Ruan Y, Liu Y, Zhang W. Effects of maternal age on pregnancy: a retrospective cohort study. [Article in Chinese] Zhonghua Yi Xue Za Zhi 2014;94:1984-8. [Abstract]

8. Beyerlein A, Schiessl B, Lack N, von Kries R. Associations of gestational weight loss with birth-related outcome: a retrospective cohort study. BJOG 2011;118:55-61.

9. Roth J, Hendrickson J, Schilling M, Stowell DW. The risk of teen mothers having low birth weight babies: implications of recent medical research for school health personnel. J Sch Health 
$1998 ; 68: 271-5$.

10. Astha Ramaiya, Ligia Kiss, Paula Baraitser, Godfrey Mbaruku and Zoe Hildon A systematic review of risk factors for neonatal mortality in Adolescent Mother's in Sub Saharan Africa BMC Research Notes 2014;7:750-6.

11. Restrepo-Méndez MC, Lawlor DA, Horta BL, Matijasevich A, Santos IS, Menezes AM, et al. The association of maternal age with birthweight and gestational age: a cross-cohort comparison. Paediatr Perinat Epidemiol 2015;29:31-40.

12. Whitworth M, Cockerill R. Antenatal management of teenage pregnancy Obstetrics. Gynaecology And Reproductıve Medicine 2010;323-9.

13. Newborn Health Epidemiology. World Health Organization; 2011. Available from: http://www.who.int/mediacentre/factsheets/20090804_figure1.jpg?ua=1.

14. Mangiaterra V, Pendse R, McClure K, Rosen J: Adolescent Pregnancy. Geneva, Switzerland: MPS Notes; 2008.

15. Uzun AK, Orhon FS, Baskan S, Ulukol B. A comparison between adolescent mothers and adult mothers in terms of maternal and infant outcomes at follow-ups. J Matern Fetal Neonatal Med 2013;26:454-8.

16. National Center for Health Statistics. Births: Preliminary Data for 2005. Available at: www.cdc.gov/nchs/births.htm.

17. Erdem G. Perinatal mortality in Turkey. Paediatr Perinat Epidemiol 2003;17:17-21.

18. Yildirim Y, Inal MM, Tinar S. Reproductive and obstetric char- acteristics of adolescent pregnancies in Turkish women. J Pediatr Adolesc Gynecol 2005;18:249-53.

19. Melekoğlu R, Evrüke C, Kafadar T, Misırlığlu S, Büyükkurt S, Özgünen FT. Perinatal Outcomes of Adolescent Pregnancy. J Turk Soc Obstet Gynecol 2013;10:213-9.

20. Keskinoglu P, Bilgic N, Picakciefe M, Giray H, Karakus N, Gunay T. Perinatal outcomes and risk factors of Turkish adolescent mothers. J Pediatr Adolesc Gynecol 2007;20:19-24.

21. Demir SC, Kadyýfçý O, Ozgünen T, Evrüke C, Vardar MA, Karaca A, et al. Pregnancy outcomes in young Turkish women. J Pediatr Adolesc Gynecol 2000;13:177-81.

22. Bacq Y. Intrahepatic cholestasis of pregnancy of pregnancy. Clin Liver Dis 1999;3:1-13.

23. Worldwide prevalence of anaemia. WHO Global Database on Anaemia Centers for Disease Control and Prevention Atlanta 1993-2005.

24. Tekbaş ÖF, Hasde M, Atay V. Bir Tip Fakültesi Kadın Hastalıkları ve Doğum Polikliniğinde İzlenen Gebelerde Anemi Sıklığı. GATA Bülteni 1997;39:20-5.

25. Bozyel ÖA, Ceylan A, Saka G, Gül K. Ben-u Sen Sağlık Ocağı Bölgesindeki Gebelerin Doğurganlık Özellikleri ve Anemi Durumları. Dicle Üniv.Tıp Fakültesi Halk Sağlığı Anabilim Dalı. IX. Halk Sağlığı Kongresi 3-6 Kasım 2004.

26. Pirinçci E, Açık Y, Bostancı M, Eren S, Beritanlı H. Elazı̆̆ İl Merkezinde Yaşayan Gebelerde Anemi Prevalansı. Firat Üniversitesi Sağlık Bilimleri Tıp Dergisi 2001;15:449-54. 